\title{
Community-acquired pneumonia due to Legionella pneumophila, the utility of PCR, and a review of the antibiotics used
}

This article was published in the following Dove Press journal:

International Journal of General Medicines

31 December 2010

Number of times this article has been viewed

\section{Paul Zarogoulidis ${ }^{1,2}$ loanna Alexandropoulou ${ }^{1,2}$ Gioulia Romanidou ${ }^{3}$ \\ Theocharis G \\ Konstasntinidis ${ }^{1,2}$ \\ Eirini Terzi ${ }^{3}$ \\ S Saridou' \\ Athanasios Stefanis' \\ Kostas Zarogoulidis ${ }^{1,2}$ \\ TC Constantinidis ${ }^{1,2}$}

'Regional Laboratory of Public Health, East Macedonia-Thrace, Komotini, Greece; ${ }^{2}$ Laboratory of Hygiene and Environmental Protection, Medical School, Democritus University of Thrace, Komotini, Greece; ${ }^{3}$ Department of Internal Medicine, General Municipal Hospital ("Sismanoglio" of Komotini), Komotini, Greece
Correspondence: Paul Zarogoulidis

9 Tasou Isaak Street,

Alexandroupolis, Greece

Tel +30697727 I 974

Fax +302310992433

Email pzarog@hotmail.com
Introduction: There are at least 40 types of Legionella bacteria, half of which are capable of producing disease in humans. The Legionella pneumophila bacterium, the root cause of Legionnaires' disease, causes $90 \%$ of legionellosis cases.

Case presentation: We describe the case of a 60 -year-old woman with a history of diabetes mellitus and arterial hypertension who was admitted to our hospital with fever and symptoms of respiratory infection, diarrhea, and acute renal failure. We used real-time polymerase chain reaction (PCR) to detect L. pneumophila DNA in peripheral blood and serum samples and urine antigen from a patient with pneumonia. Legionella DNA was detected in all two sample species when first collected.

Conclusion: Since Legionella is a cause of $2 \%$ to $15 \%$ of all community-acquired pneumonias that require hospitalization, legionellosis should be taken into account in an atypical pulmonary infection and not be forgotten. Moreover, real-time PCR should be considered a useful diagnostic method.

Keywords: Legionnaires' disease, Lionella pneumophila

\section{Introduction}

Legionella species are Gram-negative bacteria that are ubiquitous in both natural aquatic and moist soil and muddy environments and in artificial aquatic habitats. ${ }^{1,2}$ Human infection with Legionella spp. has two distinct forms: Legionnaires' disease, a more severe form of infection which includes pneumonia, and Pontiac Fever, a milder febrile flu-like illness without pneumonia. ${ }^{3}$ Legionella stands as the cause of community-acquired pneumonia (CAP) in $2 \%-15 \%$ of all CAPs that require hospitalization. The clinical and radiological features of Legionella pneumonia are nonspecific, and the diagnosis depends on laboratory tests. ${ }^{4}$ This paper reports a case of pneumonia caused by Legionella pneumophila that was admitted to the general hospital of Komotini in Greece.

\section{Case report}

A 60-year-old female with a history of diabetes mellitus, chronic obstructive pulmonary disease, and arterial hypertension with a 4-day history of watery diarrhea and temperature was admitted to our hospital. The findings from physical examinations on admission were as follows: temperature $38.6^{\circ} \mathrm{C}$, blood pressure $130 / 95 \mathrm{~mm} \mathrm{Hg}$, heart rate 117 beats $/ \mathrm{min}$, and respiratory rate 28 breaths/min. Chest auscultation revealed crackles on the left lower lung field. Laboratory findings on admission were as follows: white blood cell (WBC) count was $14,280 / \mu \mathrm{L}$, creatinine was $3.4 \mathrm{mg} / \mathrm{dL}$, the erythrocyte sedimentation 
rate (ESR) was 110/h, procacitonin (PCT) $2 \mathrm{ng} / \mathrm{mL}, \mathrm{C}$-reactive protein (CRP) $14 \mathrm{mg} / \mathrm{dL}$ (Table 1). We considered the elevated creatinine levels as acute, because at her previous laboratory tests her creatinine values never surpassed $1.3 \mathrm{mg} / \mathrm{dL}$. Arterial blood gas showed hypoxemia, as partial pressure of oxygen on air was $56 \mathrm{~mm} \mathrm{Hg}$. ${ }^{5}$ The chest X-ray showed infiltration of the left lung (Figure 1). With a clinical diagnosis of pneumonia, urine samples for L. pneumophila and Streptococcus pneumoniae antigen, gram stain sputum, and blood specimens upon admission were collected from the patient for culture testing. ${ }^{6}$ The results were reported negative. The pneumonia severity index (PSI) was evaluated as class 3 with a mortality rate of $0.9 \% .^{7}$ The patient was treated empirically with $1 \mathrm{~g}$ amoxycillin/clavulanic acid three times daily and $500 \mathrm{mg}$ clarithromycin two times daily for 2 days. Empiric antibiotic treatment was added upon admission based on elevated values of CRP, WBC, ESR, and chest X-ray findings, since early antibiotic treatment prevents progression of the disease and these markers are known to be elevated in infectious diseases. ${ }^{8,9}$ The clinical status of the patient was deteriorating, and there was a marked progression of the infiltrates on the chest X-ray; the left infiltrate progressed to bilateral shadows. The laboratory values were as follows on the 2 nd hospital

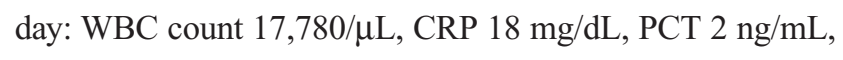
and ESR 120/h. The patient's hypoxemia increased: partial pressure of oxygen in arterial blood $\left(\mathrm{PaO}_{2}\right) 47 \mathrm{mmHg}$, partial pressure of carbon dioxide in arterial blood $\left(\mathrm{PaCO}_{2}\right) 25.4 \mathrm{~mm}$ $\mathrm{Hg}$, and $\mathrm{pH} 7.5$ (Table 1). The patient's respiratory rate increased 30/h. One day after her admission to hospital (day 2) (Figure 2), two blood samples, one serum sample and a second urine sample were taken and tested for L. pneumophila with a real-time polymerase chain reaction (PCR) kit (Aqua Screen L. pneumophila-detection kit for real-time PCR; Minerva Biolabs, Minerva, $\mathrm{OH}$ ) and with culture method. The test revealed positive for L. pneumophila. A portion of $200 \mu \mathrm{L}$ of blood and an equal volume of serum were plated on buffered charcoal yeast extract (BCYE) (Oxoid, Reading, UK) with L-cysteine, on BCYE without L-cysteine, and on GVPC (gas vesicle protein $\mathrm{C}$ ). No growth of Legionella spp. was noticed after several days of incubation. The Legionella urinary antigen detection test was positive.

The antibiotics were immediately changed to levofloxacin after the positive real-time PCR and Legionella urinary antigen detection test. The patient responded after therapy with levofloxacin, on day four (Figure 3). Her general condition, as well as radiographic and laboratory findings, gradually improved and the patient was discharged on the 21 st day of hospitalization (Figure 4).
Table I Laboratory findings

\begin{tabular}{lll}
\hline Finding & On admission & 2nd day \\
\hline WBC & $14,280 / \mu \mathrm{L}$ & $17,780 / \mu \mathrm{L}$ \\
$\quad$ Neutrophils & $89.4 \%$ & $88.3 \%$ \\
Lymphocytes & $7 \%$ & $7 \%$ \\
Basophils & $0.1 \%$ & $0.1 \%$ \\
Eosinophils & $0.1 \%$ & $0.1 \%$ \\
$\quad$ Monocytes & $3.4 \%$ & $3.5 \%$ \\
$\mathrm{AST}$ & $38 \mathrm{IU} / \mathrm{L}$ & $42 \mathrm{IU} / \mathrm{L}$ \\
$\mathrm{ALT}$ & $33 \mathrm{IU} / \mathrm{L}$ & $35 \mathrm{IU} / \mathrm{L}$ \\
$\mathrm{LDH}$ & $434 \mathrm{IU} / \mathrm{L}$ & $500 \mathrm{IU} / \mathrm{L}$ \\
$\mathrm{UR}$ & $107 \mathrm{mg} / \mathrm{dL}$ & $1110 \mathrm{mg} / \mathrm{dL}$ \\
$\mathrm{CR}$ & $3.4 \mathrm{mg} / \mathrm{dL}$ & $3.5 \mathrm{mg} / \mathrm{dL}$ \\
$\mathrm{Na}$ & $123 \mathrm{mmol} / \mathrm{L}$ & $123 \mathrm{mmol} / \mathrm{L}$ \\
$\mathrm{K}$ & $4.4 \mathrm{mmol} / \mathrm{L}$ & $4 \mathrm{mmol} / \mathrm{L}$ \\
$\mathrm{CRP}$ & $14 \mathrm{mg} / \mathrm{dL}$ & $18 \mathrm{mg} / \mathrm{dL}$ \\
$\mathrm{ESR}$ & $110 / \mathrm{h}$ & $120 / \mathrm{h}$ \\
$\mathrm{PCT}$ & $2 \mathrm{ng} / \mathrm{mL}$ & $2 \mathrm{ng} / \mathrm{mL}$ \\
$\mathrm{PaO}$ & $56 \mathrm{mmHg}$ & $47 \mathrm{mmHg}$ \\
$\mathrm{PaCO}$ & $30 \mathrm{mmHg}$ & $25 \mathrm{mmHg}$ \\
$\mathrm{PH}$ & 7.497 & 7.5 \\
\hline $\mathrm{Ab}$ & &
\end{tabular}

Abbreviations: ALT, alanine transaminase; AST, aspartate transaminase; $C R$, creatinine; CRP, C-reactive protein; ESR, erythrocyte sedimentation rate; $\mathrm{LDH}$, lactate dehydrogenase; $\mathrm{PaCO}_{2}$, partial pressure of carbon dioxide in arterial blood; $\mathrm{PaO}_{2}$, partial pressure of oxygen in arterial blood; PCT, procacitonin; UR, urea;WBC, white blood cell.

To identify the source of the infection, the patient's relatives were interviewed. Exposure histories revealed that the patient had travelled abroad and visited an operating spa pool 2 weeks before the day of onset. After she returned, she remained in her village until her admission to hospital. As there were no cooling towers or any aerosol-generating systems in an area of $2 \mathrm{~km}$ from the house, and there was no access to the spa pool abroad, environmental samples were taken only from the home water supplies, and standard methods were processed. Water samples revealed an absence of Legionella spp. from the domestic water supplies.

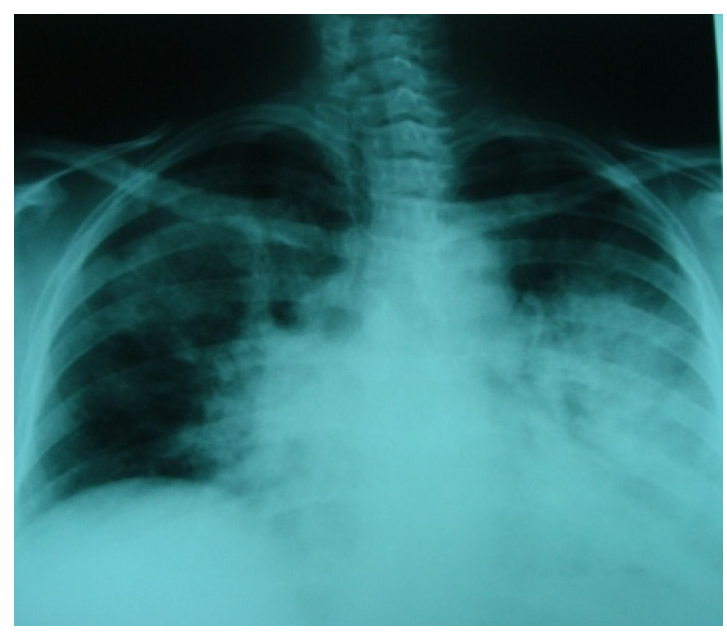

Figure I Chest X-ray upon admission. 


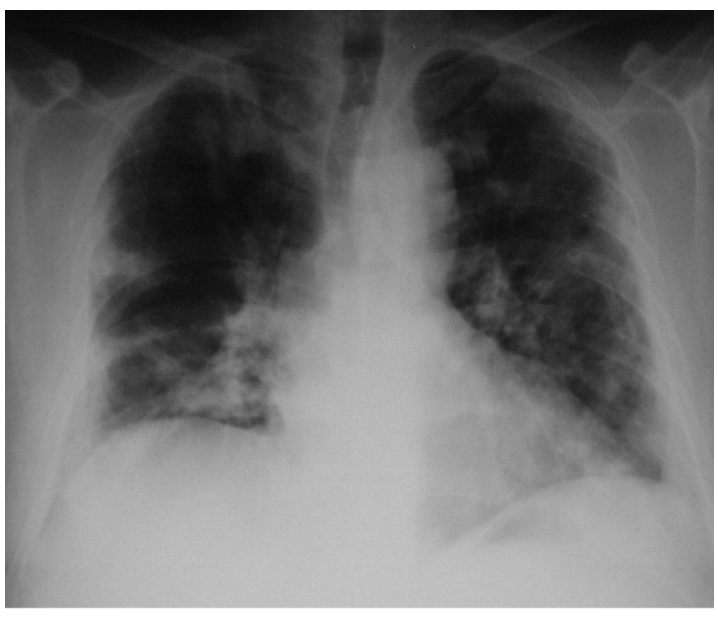

Figure 2 Chest X-ray, 2nd day.

\section{Discussion}

The incidence of Legionnaires' disease has increased in the last decade since the introduction of urinary antigen immunoassays. ${ }^{10,11}$ This test accounts for most of the diagnostics due to its high sensitivity and ease of use. ${ }^{12}$ L. pneumophila has become one of the leading causes of CAP in adults, accounting for $6 \%-14 \%$ of cases requiring hospitalization in recent studies. ${ }^{13,14}$

Legionnaires' disease occurs sporadically and in outbreaks, with the sporadic form representing $65 \%-82 \%$ of the cases. ${ }^{10,11,15}$ Nevertheless, the number of confirmed community outbreaks including more than 100 cases has increased in recent years due to the use of Legionella antigenuria. ${ }^{11,15}$ Routine testing for Legionella urinary antigen has increased the number of diagnostics of Legionnaires' disease and has allowed earlier diagnosis and treatment, greatly improving the prognosis. ${ }^{16}$ This has been particularly true for milder cases, mainly in the outbreak setting. ${ }^{17}$ However, most of the knowledge on risk factors, clinical presentation, and outcome

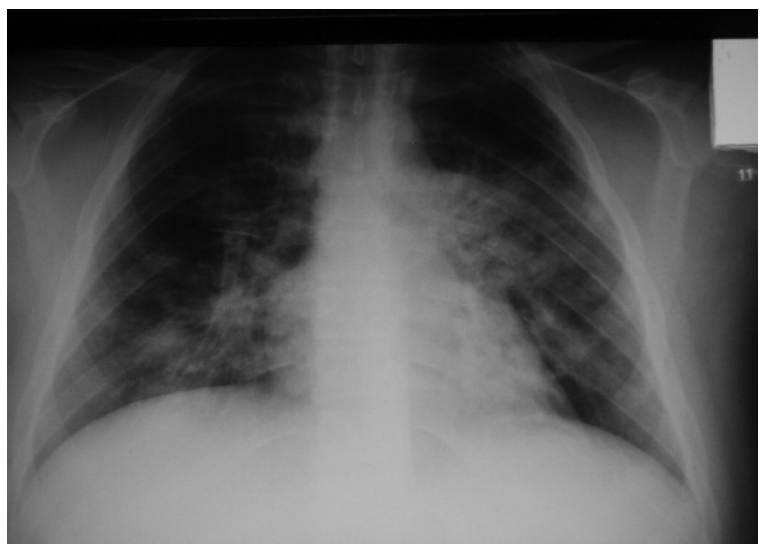

Figure 3 Chest X-ray after levofloxacin was added.

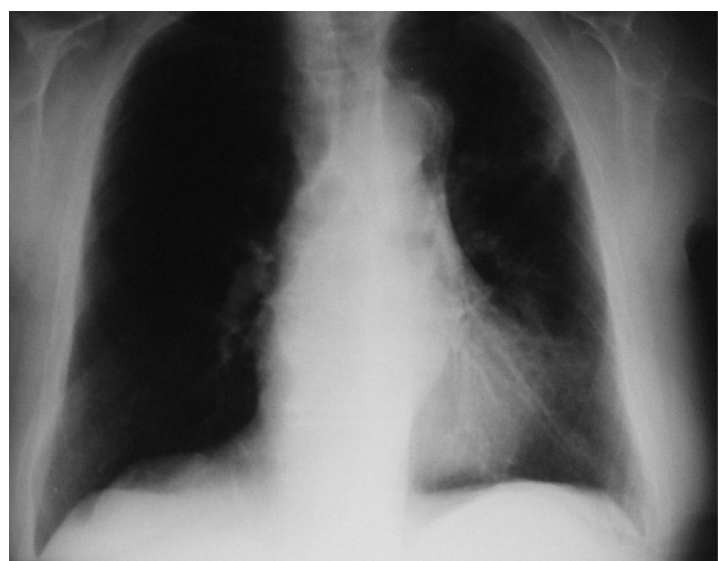

Figure 4 Chest $X$-ray on dismissal.

of community-acquired Legionnaires' disease is based on studies performed before routine urinary antigen testing was adopted. ${ }^{18,19}$ Moreover, recent community outbreaks have contributed to the better understanding of Legionnaires' disease in this setting. ${ }^{20-22}$

Legionella pneumophila has been recognized as an important cause of both CAP and nosocomial pneumonia. ${ }^{1,10,11,23}$ Environmental systems, such as air conditioning cooling towers, evaporative condensers, whirlpools, and hot spring baths have hosted and transmitted the organism. Cases of Legionella pneumonia presumably transmitted from contaminated hot spring spa water have been reported from Greece. ${ }^{23}$ The early recognition of infection due to Legionella plays a major role in its treatment and preventing mortality in patients with any underlying disease. ${ }^{24,25}$ In this case, the PCR method was lifesaving for the patient because it confirmed the infection, leading to the administration of the right treatment, whereas the first urine antigen test was misleading. This way of diagnosing Legionella has been well established in previous published studies, and it should be applied in such cases where a differential diagnostic problem exists. ${ }^{26,27}$

Legionnaires' disease is an acute bacterial infection generally caused by L. pneumophila, primarily involving the lower respiratory tract. Outbreaks have been described related to a common source of contamination. ${ }^{1}$ Erythromycin has been the treatment of choice ever since a retrospective study of the original outbreak in Philadelphia indicated a lower mortality rate with this antibiotic. Because Legionella is an intracellular pathogen, antibiotics that penetrate intracellularly are likely to be active against this pathogen. Both fluoroquinolones and macrolides penetrate cells well, and both classes demonstrate good in vitro activity. Fluoroquimolones achieve high intracellular levels and have a lower minimum inhibitory concentration against Legionella 
than erythromycin. ${ }^{28}$ They are more active than erythromycin in inhibiting L. pneumophila in different intracellular models. Three observational studies with a total of 458 patients have indicated that fluoroquinolones (mainly levofloxacin) are associated with a superior clinical response when compared with that of macrolides (erythromycin and clarithromycin), as evidenced by a shorter time to apyrexia, shorter hospital stay, and fewer drug-related complications. ${ }^{29-31}$

However, no randomized trials have been performed yet. Mortality appears to be the same. Although it has been traditional to add rifampin to erythromycin to treat severe legionellosis, an observational cohort study revealed that the addition of rifampin to clarithromycin was associated with more side effects and a longer hospitalization stay than erythromycin alone..$^{30,32}$ In all cases of severe, life-threatening pneumonia, prompt administration of appropriate antibiotics is associated with improved outcomes.

This case should urge every clinical doctor to study carefully the medical history of a patient and consider alternative diagnosis when the patient is not responding to the initial treatment. Flouoroquinolones have established an equal if not superior therapeutic profile for legionellosis based upon published studies. ${ }^{28-30}$ It should be mentioned at this point that a very important limitation of the study was that we were unable to take water samples from the spa in order to have a solid confirmation of the source of legionellosis.

\section{Conclusion}

PCR is a useful tool in the hands of the clinical doctor and should be used where possible in suspicious cases, such as the above. Also, early antibiotic treatment prevents the progression of the infection and should be administered upon admission. Finally, flouoroquinolones, and in this case levofloxacin, should be considered an effective and efficacious treatment for legionellosis.

\section{Consent}

Written informed consent was obtained from the patient's next-of-kin for publication of this case report and any accompanying images.

\section{Acknowledgments}

PZ was responsible for the medical care of the patient and was the major contributor in writing the manuscript. GR and IA were responsible for the PCR examination. KZ, TK, and ET were also responsible for the medical care. AS analyzed the radiologic examination, and TCC is the department chair. All authors read and approved the final manuscript.

\section{Disclosure}

The authors declare that they have no conflict of interest in this work.

\section{References}

1. Fields BS, Benson RF, Besser RE. Legionella and Legionnaires' disease: 25 years of investigation. Clin Microbiol Rev. 2002;15:506-526.

2. Garcia-Vidal C, Carrala J, Fernandes-Sabe N, et al. Aetiology of and risk factors for recurrent community-acquired pneumonia. Clin Microbiol Infect. 2009;15(11):1033-1038.

3. Kohno S. Pontiac fever: non-pneumonic form of legionellosis. Intern Med. 1998;7(12):1003-1004.

4. Bram MWD, Kluytmans JAJW, van den Broucke-Grauls CM, Peters MF. Utility of real-time PCR for diagnosis of Legionnaires' disease in routine clinical practice. J Clin Microbiol. 2008;46:671-677.

5. Lee WL, Slutsky AS. In: Mason, Murray and Nadel's Textbook of Respiratory Medicine. 4th ed. Philadelphia, PA: Saunders, Elsevier; 2005.

6. Anevlavis S, Petroglou N, Tzavaras A, et al. A prospective study of the diagnostic utility of sputum Gram stain in pneumonia. $J$ Infect. 2009; 59(2):83-89.

7. Fine MJ, Auble TE, Yealy DM, et al. A prediction rule to identify low-risk patients with community-acquired pneumonia. $N$ Engl J Med. 1997; 336:243-250.

8. Ortega-Deballon P, Radais F, Facy O, et al. C-Reactive protein is an early predictor of septic complications after elective colorectal surgery. World J Surg. 2010;34(4):808-814.

9. George EL, Panos A. Does a high WBC count signal infection? Nursing. 2005;35(1):20-21.

10. Joseph CA; for the European Working Group for Legionella Infections. Legionnaires' disease in Europe 2000-2002. Epidemiol Infect. 2004; 132:417-424.

11. Alvarez J, Oyaga N, Escofet A, Codony F, Orcau A, Maria Oliva J. Community-acquired legionellosis in the Barcelona region between 1992 and 1999: epidemiological characteristics and diagnostic methods. Med Clin (Barc). 2001;117:495-496.

12. Den Boer JW, Yzerman EP. Diagnosis of Legionella infection in Legionnaires' disease. Eur J Clin Microbiol Infect Dis. 2004;23: 871-878.

13. Gupta SK, Sarosi GA. The role of atypical pathogens in communityacquired pneumonia. Med Clin North Am. 2001;85:1349-1365.

14. Sopena N, Sabria M, Pedro-Botet ML, et al. Prospective study of community-acquired pneumonia of bacterial etiology in adults. Eur J Clin Microbiol Infect Dis. 1999;18:852-858.

15. Alvarez J, Dominguez A, Sabria M, et al; and the Working group of communicable diseases of the RCESP. Community outbreaks of legionellosis in Catalonia, 1990-2003 [abstract 1324]. Abstracts of the 15th European Congress of Clinical Microbiology and Infectious Diseases (Copenhaguen, Denmark). European Society of Clinical Microbiology and Infectious Diseases. 2005;11Suppl 2: 424s.

16. Benin AL, Benson RF, Besser RE. Trends in Legionnaires' disease, 1980-1998: declining mortality and new patterns of diagnosis. Clin Infect Dis. 2002;35:1039-1046.

17. Formica N, Yates M, Beers M, et al. The impact of diagnosis by Legionella urinary antigen test on the epidemiology and outcomes of Legionnaires' disease. Epidemiol Infect. 2001;127:275-280.

18. Marston BJ, Lipman HB, Breiman RF. Surveillance for Legionnaires' disease. Risk factors for morbidity and mortality. Arch Intern Med. 1994;154:2417-2422.

19. Straus WL, Plouffe JF, File TM Jr, et al. Risk factors for domestic acquisition of legionnaires' disease. Ohio Legionnaires' Disease Group. Arch Intern Med. 1996;156:1685-1692.

20. Garcia-Fulgueiras A, Navarro C, Fenoll D, et al. Legionnaires' disease outbreak in Murcia, Spain. Emerg Infect Dis. 2003;9: 915-921. 
21. Greig JE, Carnie JA, Tallis GF, et al. An outbreak of Legionnaires' disease at the Melbourne Aquarium, April 2000: investigation and case-control studies. Med J Aust. 2004;180:566-572.

22. Den Boer JW, Yzerman EP, Schellekens J, et al. A large outbreak of Legionnaires' disease at a flower show, the Netherlands, 1999. Emerg Infect Dis. 2002;8:37-43.

23. Mavridou A, Smeti E, Mandilara G, et al. Prevalence study of Legionella spp. contamination in Greek hospitals. Int J Environ Health Res. 2008; 18(4):295-304.

24. Sopena N, Force L, Pedro-Botet ML, et al. Sporadic and epidemic community legionellosis: two faces of the same illness. Eur Respir J. 2007;29:138-142.

25. Pedro-Botet ML, Sabria Leal M, Haro M, et al. Nosocomial and community-aquired Legionella pneumonia:clinical comparative analysis. Eur Respir J. 1995;8:1929-1933.

26. Welti M, Jaton K, Altwegg M, Sahli R, Wenger A, Bille J. Development of a multiplex real-time quantitative PCR assay to detect Chlamydia pneumoniae, Legionella pneumophila and Mycoplasma pneumoniae in respiratory tract secretions. Diagn Microbiol Infect Dis. 2003; 45(2):85-95.
27. Ginevra C, Barranger C, Ros A, et al. Development and evaluation of Chlamylege, a new commercial test allowing simultaneous detection and identification of Legionella, Chlamydophila pneumoniae, and Mycoplasma pneumoniae in clinical respiratory specimens by multiplex PCR. J Clin Microbiol. 2005;43(7):3247-3254.

28. Pedro-Botet L, Yu VL. Legionella: macrolides or quinolones? Clin Microbiol Infect. 2006;12(Suppl 3):25-30.

29. Sabria M, Pedro-Botet ML, Gomez J, et al; Legionnaires Disease Therapy Group. Fluoroquimolones vs macrolides in the treatment of Legionnaires' disease. Chest. 2005;128:1401-1405.

30. Mykietiuk A, Carratala J, Fernandez-Sabe N, et al. Clinical outcomes for hospitilized patients with Legionella pneumonia in the antigenuria era: the influence of levofloxacin therapy. Clin Infect Dis. 2005;40: 794-799.

31. Yu VL, Greenberg RN, Zadeikis N, et al. Levofloxacin efficacy in the treatment of community-aquired legionellosis. Chest. 2004;125: 2135-2139.

32. Grau S, Mateu-de Antonio J, Ribes E, Salvado M, Garces JM, Garau J. Impact of rifampincin to clarithromycin in Legionella pneumophila pneumonia. Intern J Antimicrob Agents. 2006;28:249-252.
International Journal of General Medicine

\section{Publish your work in this journal}

The International Journal of General Medicine is an international, peer-reviewed open-access journal that focuses on general and internal medicine, pathogenesis, epidemiology, diagnosis, monitoring and treatment protocols. The journal is characterized by the rapid reporting of reviews, original research and clinical studies across all disease areas.

\section{Dovepress}

A key focus is the elucidation of disease processes and management protocols resulting in improved outcomes for the patient.The manuscript management system is completely online and includes a very quick and fair peer-review system. Visit http://www.dovepress.com/ testimonials.php to read real quotes from published authors.

Submit your manuscript here: http://www.dovepress.com/international-journal-of-general-medicine-journal 